Division of Geological \& Geophysical Surveys

RAW-DATA FILE 2004-2

\title{
MAJOR-OXIDE, MINOR-OXIDE, AND TRACE-ELEMENT GEOCHEMICAL DATA FROM ROCKS COLLECTED IN THE LIVENGOOD QUADRANGLE, ALASKA IN 2001 AND 2003
}

by

J.E. Athey, M.B. Werdon, D.J. Szumigala, R.J. Newberry, S.A. Hicks, and H.A. Erickson

$\$ 15.00$

January 2004

THIS REPORT HAS NOT BEEN REVIEWED FOR TECHNICAL CONTENT OR FOR CONFORMITY TO THE

EDITORIAL STANDARDS OF ADGGS

Released by

STATE OF ALASKA

DEPARTMENT OF NATURAL RESOURCES

Division of Geological \& Geophysical Surveys 3354 College Road

Fairbanks, Alaska 99709-3707 
CONTENTS

INTRODUCTION.

ANALYTICAL METHODS

TABLES

TABLE 1. CONCENTRATIONS OF MAJOR OXIDES, MINOR OXIDES, AND TRACE ELEMENTS IN ROCK SAMPLES COLLECTED IN THE LIVENGOOD QUADRANGLE......... 2

TABLE 2. LOCATION AND DESCRIPTION OF ROCK SAMPLES COLLECTED FOR MAJOROXIDE, MINOR-OXIDE, AND TRACE-ELEMENT ANALYSES IN THE LIVENGOOD

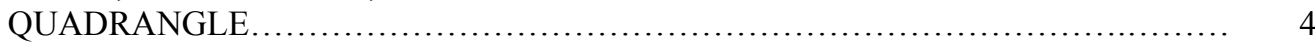

TABLE 3. CONCENTRATION OF TRACE ELEMENTS IN ROCK SAMPLES COLLECTED IN THE LIVENGOOD QUADRANGLE.

TABLE 4. LOCATION AND DESCRIPTION OF ROCK SAMPLES COLLECTED FOR TRACEELEMENT ANALYSIS IN THE LIVENGOOD QUADRANGLE.................... 10

TABLE 5. LIMITS AND ANALYTICAL METHODS FOR THE MAJOR-OXIDE, MINOR-OXIDE,

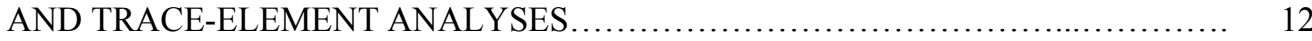

TABLE 6. LIMITS AND ANALYTICAL METHODS FOR TRACE-ELEMENT GEOCHEMICAL ANALYSIS

\section{SHEET}

SHEET 1. LOCATION OF ROCK SAMPLES ANALYZED FOR MAJOR-OXIDE, MINOR-OXIDE, AND TRACE-ELEMENT GEOCHEMISTRY IN THE LIVENGOOD B-3, B-4, C-3, AND C-4 QUADRANGLES, ALASKA IN 2003. 1 SHEET (IN POCKET)

MAP A. MAJOR OXIDES, MINOR OXIDES, AND TRACE ELEMENTS

MAP B. TRACE-ELEMENT GEOCHEMISTRY

Note: $\quad$ This report (including all analytical data, tables, and map sheets) is available in digital format from the ADGGS web site (http://wwwdggs.dnr.state.ak.us) at no charge. The digital data are available as PDF files and Excel spreadsheets. 


\title{
MAJOR-OXIDE, MINOR-OXIDE, AND TRACE-ELEMENT GEOCHEMICAL DATA FROM ROCKS \\ COLLECTED IN THE LIVENGOOD QUADRANGLE, ALASKA IN 2001 AND 2003
}

\author{
by \\ J.E. ATHEY, M.B. WERDON, D.J. SZUMIGALA, R.J. NEWBERRY, S.A. HICKS, AND H.A. ERICKSON
}

\section{INTRODUCTION}

Mineral resource personnel from the Alaska Division of Geological and Geophysical Surveys carried out a geological field survey, including mapping and sampling in the Livengood quadrangle, Alaska from May 28 through June 16, 2003. The fieldwork provides basic information critical to building an understanding of Alaska's geology and is part of the Alaska Airborne Geophysical/Geological Mineral Inventory Program, an integrated program of airborne geophysical surveys followed by geological mapping. Alaska Airborne Geophysical/Geological Mineral Inventory Program is a special multi-year investment by the State of Alaska to expand Alaska's geologic and mineral resources knowledge base, catalyze future privatesector mineral exploration and development, and guide state planning. The geologic mapping is also funded in part by the U.S. Geological Survey STATEMAP program.

During 2001, 6 rock samples were collected for geochemical trace-element analysis. During 2003, 54 rock samples were collected for geochemical trace-element analysis and 50 samples were collected for wholerock (major- and minor-oxides and petrogenetically important trace-element data) analysis. Visibly mineralized samples and samples with features that may indicate potential mineralization are preferentially selected for trace-element analysis. The locations of these samples are shown on Sheet 1, Maps A (wholerock geochemistry) and B (trace-element geochemistry). Location data (in UTM coordinates based on the Clarke 1866 spheroid, NAD27 datum, UTM zone 6 projection), descriptions, and analytical results for each sample are tabulated in Tables 1 through 4.

\section{ANALYTICAL METHODS}

All whole-rock analyses (Table 1) and trace-element geochemistry (Table 3) were performed by ALS Chemex in 2003. Rock samples were crushed so that $70 \%$ of the material passed through a $-10(2 \mathrm{~mm})$ mesh screen. Rock samples were then pulverized so that $85 \%$ of the material passed through a -200 (75 $\mu \mathrm{m})$ mesh screen. Riffle splitters ensured accurate sampling of 30-gram and 200-gram samples.

Major and minor oxides were determined by X-ray fluorescence spectrometry (XRF) following a lithium metaborate fusion. Petrogenetically important trace elements ( $\mathrm{Ba}, \mathrm{Nb}, \mathrm{Sr}, \mathrm{Y}$, and $\mathrm{Zr}$ ) were also analyzed using XRF methods on a pressed powder pellet. Analytical detection limits for these data are tabulated in Table 5.

Gold was analyzed on a 30-gram split using either Fire Assay - Atomic Absorption Spectroscopy (FAAAS, Au1) or Inductively Coupled Plasma - Mass Spectroscopy (ICP-MS, Au2) methods following Fire Assay Fusion. One sample was re-analyzed for gold with a gravimetric finish following Fire Assay Fusion (FA- Gravimetric, Au3). Platinum and palladium were analyzed by the Inductively Coupled Plasma - Mass Spectroscopy (ICP-MS) method following Fire Assay Fusion. Trace elements were analyzed by the Inductively Coupled Plasma - Atomic Emission Spectroscopy (ICP-AES) methods following acid digestion ( $\mathrm{HF}-\mathrm{HNO}_{3}-\mathrm{HClO}_{4}$ and $\mathrm{HCl}$ leach). Arsenic $>1 \%$ was re-analyzed by Atomic Absorption Spectroscopy (AAS) after aqua regia digestion. Mercury was analyzed by Cold Vapor Atomic Absorption Spectroscopy. Trace-element detection limits are tabulated in Table 6. 
Table 1. Concentrations of major oxides, minor oxides, and trace elements in rock samples collected in the Livengood Quadrangle.

Note: --- = not analyzed.

\begin{tabular}{|c|c|c|c|c|c|c|c|c|c|c|c|c|c|c|c|c|c|c|c|c|c|}
\hline SAMPLE & $\begin{array}{c}\mathrm{Al} 2 \mathrm{O} 3 \\
\% \\
\end{array}$ & $\begin{array}{c}\mathrm{BaO} \\
\% \\
\end{array}$ & $\begin{array}{c}\mathrm{CaO} \\
\% \\
\end{array}$ & $\begin{array}{c}\mathrm{Cr} 2 \mathrm{O} 3 \\
\% \\
\end{array}$ & \begin{tabular}{|c|}
$\mathrm{Fe} 2 \mathrm{O} 3$ \\
$\%$ \\
\end{tabular} & $\begin{array}{c}\mathrm{K} 2 \mathrm{O} \\
\% \\
\end{array}$ & $\begin{array}{c}\mathrm{MgO} \\
\% \\
\end{array}$ & $\begin{array}{c}\mathrm{MnO} \\
\% \\
\end{array}$ & $\begin{array}{c}\mathrm{Na} 2 \mathrm{O} \\
\% \\
\end{array}$ & $\begin{array}{c}\mathrm{P} 2 \mathrm{O} 5 \\
\% \\
\end{array}$ & $\begin{array}{c}\mathrm{SiO} 2 \\
\% \\
\end{array}$ & $\begin{array}{c}\mathrm{SrO} \\
\% \\
\end{array}$ & $\begin{array}{c}\mathrm{TiO} 2 \\
\% \\
\end{array}$ & $\begin{array}{c}\text { LOI } \\
\% \\
\end{array}$ & $\begin{array}{c}\text { Total } \\
\% \\
\end{array}$ & $\begin{array}{c}\mathrm{Ba} \\
\mathrm{ppm}\end{array}$ & $\begin{array}{c}\mathrm{Rb} \\
\mathrm{ppm}\end{array}$ & $\begin{array}{c}\mathrm{Sr} \\
\mathrm{ppm}\end{array}$ & $\begin{array}{c}\mathrm{Nb} \\
\mathrm{ppm}\end{array}$ & $\begin{array}{c}\mathrm{Zr} \\
\mathrm{ppm}\end{array}$ & $\begin{array}{c}\mathrm{Y} \\
\mathrm{ppm}\end{array}$ \\
\hline 2003JEA3B & 15.66 & 0.04 & 8.75 & 0.03 & 12.22 & 0.29 & 6.90 & 0.13 & 2.86 & 0.31 & 48.37 & 0.04 & 1.91 & 2.46 & 99.96 & 330 & 5 & 319 & 18 & 131 & 26 \\
\hline 2003 & 18 & 0.02 & 8.04 & 0.02 & 1.23 & 0.23 & .96 & 0.18 & 4.20 & 0.09 & 50.50 & 0.03 & 0.78 & 2.49 & 99.96 & 200 & 8 & 259 & 3 & 55 & \\
\hline $2003 \mathrm{~J}$ & .59 & 0.04 & 4.25 & 0.01 & 12.66 & 0.41 & 5.71 & 0.13 & 3.49 & 0.44 & 48.83 & 0.02 & 3.29 & 4.10 & 99.98 & 240 & 4 & 364 & 17 & 187 & 2 \\
\hline 2003 & 19 & 0.03 & 25.07 & 0.01 & 0.59 & 0.02 & 13.35 & 0.12 & 0.01 & 0.09 & 23.54 & 0.01 & 0.09 & 36.80 & 99.92 & -- & -- & -- & -- & -- & \\
\hline 2003J & .93 & 0.04 & 9.06 & $<0.01$ & 11.58 & 0.24 & 3.86 & 0.11 & 4.25 & 0.45 & 46.27 & 0.06 & 1.98 & 3.51 & 99.34 & 370 & 4 & 554 & 29 & 200 & \\
\hline 2003 & 32 & 0.05 & 3.00 & 0.04 & 5.86 & 1.35 & 2.89 & 0.11 & 0.11 & 0.09 & 69.99 & 0.02 & 0.42 & 6.65 & 8.90 & 530 & 38 & 132 & 6 & 90 & 2 \\
\hline 2003JEA234A & .58 & 0.38 & 3.65 & $<0.01$ & 4.00 & 6.09 & 1.40 & 0.09 & 3.29 & 0.32 & 58.97 & 0.11 & 0.43 & 5.64 & 98.94 & 3300 & 183 & 991 & 21 & 372 & 2 \\
\hline $2003 \mathrm{~J}$ & 3.29 & 0.22 & 1.43 & $<0.01$ & 9.49 & 5.08 & 1.40 & 0.24 & 4.06 & 0.10 & 51.27 & 0.02 & 1.17 & 6.88 & 99.65 & 1860 & 125 & 135 & 57 & 464 & \\
\hline 2003JEA236A & 13.31 & 0.14 & 0.58 & 0.01 & 5.49 & 3.81 & 1.72 & 0.07 & 0.06 & 0.05 & 66.97 & 0.02 & 0.51 & 6.14 & 98.88 & 1410 & 140 & 92 & 70 & 874 & - \\
\hline 2003JEA237B & .56 & 0.21 & 1.45 & $<0.01$ & 6.58 & 4.30 & 1.33 & 0.14 & 0.55 & 0.09 & 64.70 & 0.03 & 0.77 & 5.22 & 99.92 & 1950 & 138 & 141 & 36 & 359 & 5 \\
\hline 2003 & 12.75 & 0.05 & 0.84 & $<0.01$ & 5.55 & 1.06 & 0.29 & 0.01 & 5.52 & 0.06 & 68.80 & 0.03 & 0.61 & 4.20 & 99.79 & 490 & 23 & 128 & 37 & 452 & \\
\hline 2003 & .50 & 0.13 & 0.17 & $<0.01$ & 6.22 & 3.90 & 0.89 & 0.08 & 1.34 & 0.04 & 65.72 & 0.02 & 0.56 & 4.70 & 98.28 & 1280 & 171 & 42 & 71 & 794 & 9 \\
\hline 2003 & .93 & & 0.29 & 0.01 & 6.26 & 3.73 & 1.03 & & 1.00 & & 66.40 & 0.01 & .51 & & .44 & 1200 & 168 & 33 & & 45 & 11 \\
\hline 2003JEA239B & 2.49 & 0.04 & 0.35 & $<0.01$ & 2.88 & 0.89 & 0.38 & 0.02 & 5.51 & 0.07 & 73.68 & 0.01 & 0.60 & 1.74 & 98.67 & 330 & 20 & 76 & 84 & 2160 & 28 \\
\hline $2003 \mathrm{~J}$ & .37 & 0.22 & 0.18 & $<0.01$ & 2.07 & 7.64 & 0.33 & $<0.01$ & 2.73 & 0.09 & 62.64 & 0.02 & 1.18 & 49 & 3.95 & 1980 & 221 & 141 & 65 & 883 & 100 \\
\hline 2003J & .13 & 0.26 & 4.01 & $<0.01$ & 5.78 & 1.12 & 2.12 & 0.08 & 4.76 & 0.37 & 59.63 & 0.15 & 0.53 & 5.82 & 3.76 & 2240 & 44 & 1400 & 12 & 372 & 2 \\
\hline 2003JEA & .60 & 0.48 & 0.33 & $<0.01$ & 3.46 & 7.89 & 0.30 & $<0.01$ & 2.93 & 0.39 & 62.36 & 0.10 & 0.62 & 3.03 & 98.50 & 3760 & 223 & 921 & 22 & 415 & 2 \\
\hline $2003 \mathrm{~J}$ & 73 & 0.02 & 0.30 & $<0.01$ & 1.01 & 1.94 & 0.19 & $<0.01$ & 6.34 & 0.03 & 70.10 & 0.04 & 0.23 & 1.53 & 98.45 & 170 & 112 & 359 & & 499 & 2 \\
\hline $2003 \mathrm{~N}$ & 5.85 & 0.02 & 6.96 & $<0.01$ & 11.31 & 0.24 & 4.29 & 0.13 & 4.92 & 0.16 & 52.18 & 0.04 & 1.14 & 2.20 & 99.42 & 100 & 4 & 336 & $<2$ & 97 & 3 \\
\hline 2003 & 5.76 & 0.35 & 1.04 & 0.02 & 4.11 & 7.27 & 3.32 & 0.05 & 1.94 & .15 & 61.35 & 0.11 & 0.63 & 3.23 & 9.32 & 2800 & 249 & 995 & 15 & 256 & 1 \\
\hline $2003 \mathrm{~N}$ & 5.77 & 0.01 & 6.32 & $<0.01$ & 10.71 & 0.26 & 5.17 & 0.12 & 4.90 & 0.11 & 53.11 & 0.03 & 0.89 & 1.82 & 9.22 & 100 & 8 & 245 & $<2$ & 64 & 2 \\
\hline 2003MBW15A & 0.07 & 0.01 & 29.66 & $<0.01$ & 0.04 & 0.01 & 19.64 & $<0.01$ & 0.11 & 0.04 & 6.30 & 0.01 & $<0.01$ & 43.70 & 99.58 & --- & -- & --- & -- & --- & - \\
\hline 2003MBW42A & 2.90 & 0.01 & 14.21 & 0.01 & 4.69 & 0.30 & 6.38 & & 2.18 & 0.03 & 45.87 & 0.02 & 0.31 & 2.89 & 99.86 & 20 & 4 & 155 & & 12 & \\
\hline 2003MBW53A & 13.80 & 0.01 & 12.38 & 0.01 & 8.85 & 0.07 & 4.64 & 0.22 & 1.20 & 0.14 & 52.22 & 0.03 & 0.69 & 5.15 & 99.41 & 40 & 2 & 215 & $<2$ & 78 & 27 \\
\hline 2003MBW87.2A & 17.66 & 0.09 & 2.97 & $<0.01$ & 13.84 & 0.28 & 4.18 & 0.17 & 5.02 & 0.93 & 49.25 & 0.04 & 1.92 & 2.67 & 99.00 & 740 & 3 & 260 & 55 & 671 & 8 \\
\hline 2003 & 12.84 & 0.01 & 17.13 & 0.15 & 4.98 & 0.42 & 10.37 & 0.14 & 1.56 & 0.02 & 47.06 & 0.01 & 0.31 & 3.35 & 98.34 & 100 & 8 & 76 & 24 & 4 & 1 \\
\hline 2003MBW120A & 16.60 & 0.21 & 1.75 & $<0.01$ & 9.75 & 3.62 & 1.83 & 0.35 & 4.21 & 0.14 & 53.31 & 0.01 & 1.12 & 5.16 & 98.06 & 1990 & 93 & 134 & 45 & 267 & 4 \\
\hline 2003MBW240A & 0.15 & 0.02 & 32.52 & 0.01 & 0.14 & 0.02 & 17.97 & 0.01 & $<0.01$ & 0.11 & 2.06 & 0.01 & 0.08 & 45.00 & 98.10 & -- & -- & -- & -- & --- & - \\
\hline 2003MBW249B & 16.34 & 0.19 & 2.82 & $<0.01$ & 9.82 & 3.14 & 2.39 & 0.27 & 4.19 & 0.13 & 53.40 & 0.02 & 1.09 & 4.76 & 98.56 & 1750 & 84 & 136 & 36 & 244 & 35 \\
\hline 2003MBW258A & 16.33 & 0.17 & 3.01 & $<0.01$ & 9.84 & 2.97 & 2.39 & 0.27 & 4.14 & 0.13 & 53.35 & 0.02 & 1.07 & 4.78 & 98.48 & 1650 & 79 & 133 & 36 & 237 & 43 \\
\hline 2003RN53A & 15.35 & 0.05 & 6.41 & $<0.01$ & 17.11 & 0.64 & 6.44 & 0.16 & 2.92 & 0.60 & 41.96 & 0.05 & 3.89 & 4.46 & 100.05 & 290 & 9 & 427 & 27 & 265 & 3 \\
\hline 2003RN121A & 15.79 & 0.31 & 0.66 & 0.01 & 4.92 & 6.73 & 2.96 & 0.02 & 2.04 & 0.27 & 62.36 & 0.09 & 0.58 & 2.58 & 99.34 & 2550 & 247 & 827 & 15 & 254 & 2 \\
\hline 2003RN130A & 15.55 & 0.01 & 8.89 & 0.01 & 9.47 & 0.22 & 5.46 & 0.11 & 3.60 & 0.10 & 52.51 & 0.01 & 0.71 & 2.24 & 98.89 & 100 & 3 & 54 & $<2$ & 52 & 15 \\
\hline
\end{tabular}


Table 1. Concentrations of major oxides, minor oxides, and trace elements in rock samples collected in the Livengood Quadrangle. Note: --- = not analyzed.

\begin{tabular}{|c|c|c|c|c|c|c|c|c|c|c|c|c|c|c|c|c|c|c|c|c|c|}
\hline SAMPLE & $\mathrm{Al} 2 \mathrm{O} 3$ & $\mathrm{BaO}$ & $\mathrm{CaO}$ & $\mathrm{Cr} 2 \mathrm{O} 3$ & $\mathrm{Fe} 2 \mathrm{O} 3$ & $\mathrm{~K} 2 \mathrm{O}$ & $\mathrm{MgO}$ & $\mathrm{MnO}$ & $\mathrm{Na} 2 \mathrm{O}$ & $\mathrm{P} 2 \mathrm{O} 5$ & $\mathrm{SiO} 2$ & $\mathrm{SrO}$ & $\mathrm{TiO} 2$ & LOI & Total & $\mathrm{Ba}$ & $\mathrm{Rb}$ & $\mathrm{Sr}$ & $\mathrm{Nb}$ & $\mathrm{Zr}$ & $\mathrm{Y}$ \\
\hline 2003RN209A & 15.61 & 0.02 & 11.82 & 0.04 & 9.83 & 2.20 & 7.81 & 0.20 & 1.23 & 0.06 & 44.94 & 0.01 & 0.81 & 4.92 & 99.51 & 110 & 28 & 28 & $<2$ & 44 & 23 \\
\hline 2003RN209A & 5.61 & 0.02 & 11.82 & 0.04 & 83 & 2.20 & 7.81 & 0.20 & 1.23 & 0.06 & 44.94 & 0.01 & 0.81 & 4.92 & 99.51 & 110 & 28 & 28 & $<2$ & 44 & 23 \\
\hline $2003 Z 211 \mathrm{C}$ & 15.91 & 0.48 & 1.93 & $<0.01$ & 7.93 & 10.59 & 2.23 & 0.09 & 0.59 & 0.61 & 55.20 & 0.12 & 0.84 & 2.73 & 99.24 & 3820 & 341 & 1035 & 21 & 389 & 17 \\
\hline $2003 Z 212 A$ & 15.22 & 0.06 & 5.94 & 0.01 & 16.49 & 0.56 & 6.91 & 0.19 & 2.71 & 0.54 & 42.59 & 0.02 & 3.89 & 3.77 & 98.92 & 520 & 7 & 423 & 25 & 257 & 34 \\
\hline $2003 Z 217 A$ & 0.24 & 0.02 & 53.10 & $<0.01$ & 0.29 & 0.01 & 1.95 & 0.02 & 0.02 & 0.07 & 0.85 & 0.02 & 0.09 & 43.10 & 99.78 & -- & --- & --- & -- & --- & -- \\
\hline $2003 Z 218 A$ & 16.45 & 0.04 & 6.42 & 0.01 & 13.19 & 0.27 & 7.60 & 0.16 & 3.21 & 0.38 & 44.49 & 0.02 & 2.17 & 4.84 & 99.25 & 320 & 4 & 311 & 23 & 189 & 30 \\
\hline $2003 Z 135 A$ & 0.06 & 0.02 & 26.84 & $<0.01$ & 0.16 & 0.01 & 14.61 & 0.01 & 0.02 & 0.01 & 20.07 & 0.01 & 0.07 & 36.50 & 98.39 & --- & -- & -- & -- & --- & -- \\
\hline $2003 Z 142 A$ & 14.10 & 0.08 & 6.27 & $<0.01$ & 14.09 & 0.80 & 4.30 & 0.22 & 3.32 & 0.24 & 49.67 & 0.02 & 2.71 & 3.30 & 99.12 & 660 & 18 & 259 & 14 & 143 & 32 \\
\hline 2003Z149B & 15.23 & 0.02 & 7.77 & 0.04 & 8.11 & 1.48 & 8.06 & 0.27 & 3.55 & 0.07 & 50.41 & 0.02 & 0.72 & 3.70 & 99.43 & 130 & 22 & 98 & $<2$ & 36 & 19 \\
\hline $2003 Z 175 B$ & 14.31 & 0.02 & 19.28 & 0.01 & 12.86 & 0.08 & 6.96 & 0.27 & 0.18 & 0.09 & 39.83 & 0.01 & 0.93 & 4.70 & 99.54 & 70 & 2 & 12 & 2 & 52 & 20 \\
\hline $2003 Z 175 C$ & 15.34 & 0.03 & 16.86 & 0.03 & 11.70 & 0.05 & 10.26 & 0.27 & 0.14 & 0.37 & 35.14 & 0.01 & 3.57 & 5.97 & 99.75 & 150 & 2 & 30 & 4 & 102 & 26 \\
\hline $2003 Z 185 A$ & 13.89 & 0.03 & 10.51 & 0.02 & 13.06 & 0.16 & 6.57 & 0.16 & 3.05 & 0.14 & 46.80 & 0.01 & 1.84 & 3.68 & 99.92 & 150 & 5 & 36 & $<2$ & 102 & 40 \\
\hline $2003 Z 32 A$ & 9.39 & 0.04 & 0.27 & 0.01 & 4.55 & 1.80 & 1.15 & 0.06 & 1.07 & 0.08 & 78.21 & 0.01 & 0.53 & 2.68 & 99.86 & 390 & 71 & 47 & 10 & 86 & 12 \\
\hline $2003 Z 239 A$ & 14.68 & 0.18 & 0.17 & $<0.01$ & 2.54 & 4.03 & 0.44 & $<0.01$ & 1.00 & 0.04 & 73.20 & 0.01 & 0.54 & 2.40 & 99.22 & 1790 & 177 & 55 & 83 & 784 & 102 \\
\hline $2003 Z 255 A$ & 15.78 & 0.02 & 8.47 & $<0.01$ & 11.39 & 0.28 & 4.68 & 0.14 & 4.20 & 0.09 & 52.50 & 0.05 & 0.74 & 1.27 & 99.59 & 190 & 8 & 218 & $<2$ & 45 & 19 \\
\hline $2003 Z 60 A$ & 14.96 & 0.04 & 8.18 & 0.04 & 15.66 & 0.77 & 7.16 & 0.13 & 2.47 & 0.29 & 38.27 & 0.03 & 2.20 & 8.11 & 98.32 & 350 & 9 & 285 & 12 & 154 & 26 \\
\hline $2003 Z 74 A$ & 0.14 & 0.02 & 13.83 & 0.01 & 0.59 & 0.04 & 9.32 & 0.01 & 0.06 & 0.06 & 53.14 & $<0.01$ & 0.09 & 21.30 & 98.61 & --- & - & -- & - & --- & - \\
\hline $2003 Z 78 A$ & 16.12 & 0.05 & 5.16 & 0.01 & 14.20 & 0.44 & 5.89 & 0.15 & 3.22 & 0.49 & 44.60 & 0.02 & 3.23 & 6.12 & 99.70 & 400 & 10 & 338 & 22 & 220 & 30 \\
\hline
\end{tabular}


Table 2. Location and description of rock samples collected for major-oxide, minor-oxide, and trace-element analyses in the Livengood Quadrangle.

\begin{tabular}{|c|c|c|c|}
\hline SAMPLE & UTM E & UTM N & DESCRIPTION \\
\hline 2003JEA3B & 432274 & 7271250 & Basalt; massive. \\
\hline 2003JEA29A & 431621 & 7266629 & Gabbro; green, very fine grained. \\
\hline 2003JEA42A & 430722 & 7268544 & Greenstone; massive. \\
\hline 2003JEA68A & 423346 & 7267935 & Siliceous dolomite. \\
\hline 2003JEA76A & 421683 & 7265267 & Basalt; amygdaloidal, red-brown weathering. \\
\hline 2003JEA90A & 431450 & 7267738 & Greenstone. \\
\hline 2003JEA234A & 427625 & 7265475 & Syenite porphyry; $20 \%$ feldspar phenocrysts $=/<1 \mathrm{~cm}$ long, $2 \%$ quartz phenocrysts $<0.4 \mathrm{~cm}$ in diameter; tan, fine grained matrix. \\
\hline 2003JEA235A & 428443 & 7266477 & Quartz monzonite; blue gray, feldspar porphyry (10\% phenocrysts, $1 \mathrm{~cm}$ long), $15-20 \%$ mafic minerals altered to iron oxide and clay. \\
\hline 2003JEA236A & 428443 & 7266477 & Granite; light gray to white, flow banded, feldspar $1-2 \mathrm{~mm}$ long, $20 \%$ quartz phenocrysts, $5 \%$ disseminated pyrite. \\
\hline 2003JEA237B & 428443 & 7266477 & $\begin{array}{l}\text { Granite porphyry; propylitic alteration, amygdules } 2 \mathrm{~mm} \text { in diameter filled with quartz and minor iron oxide and carbonate, feldspar } \\
\text { phenocrysts } 0.4 \mathrm{~cm} \text { long. }\end{array}$ \\
\hline 2003JEA237C & 428443 & 7266477 & Porphyry; gray, feldspar and quartz phenocrysts, pyrite disseminated and in veins cutting phenocrysts. \\
\hline 2003JEA238A & 429812 & 7266506 & $\begin{array}{l}\text { Granite; gray, foliated, porphyritic feldspar } 3 \mathrm{~mm} \text { long, xenoliths of more igneous rock, arsenopyrite and pyrite disseminated and in veins } \\
\text { with quartz (2 mm wide). }\end{array}$ \\
\hline 2003JEA238B & 429812 & 7266506 & Granite; dark gray-black, porphyritic feldspar 2 mm long. \\
\hline 2003JEA239B & 429812 & 7266506 & Granite; gray-green, porphyritic feldspar. \\
\hline 2003JEA241A & 429020 & 7266650 & Plutonic; gray-green, $2 \%$ feldspar phenocrysts $=/<3 \mathrm{~mm}$ long. \\
\hline 2003JEA243A & 429400 & 7266500 & $\begin{array}{l}\text { Plutonic dike; light gray, fine grained }(2-3 \mathrm{~mm}) \text {, equigranular, highly sericite altered, disseminated pyrite and arsenopyrite }=<3 \mathrm{~mm} \text { in } \\
\text { size. }\end{array}$ \\
\hline 2003JEA301A & 430132 & 7266081 & Monzonite/syenite; cream, sericite altered, feldspar =/<1 cm long, biotite. \\
\hline 2003JEA310A & 430106 & 7266096 & Granite; white, fine-medium grained, few porphyritic K-feldspar </= $1 \mathrm{~cm}$ long, xenolith of sedimentary (?) material. \\
\hline 2003MBW3A & 428230 & 7266930 & Gabbro; dark gray, fine grained, equigranular, homogeneous, massive, $60 \%$ plagioclase, $40 \%$ clinopyroxene and hornblende. \\
\hline 2003MBW9B & 430052 & 7266066 & Quartz monzonite dike; light-medium gray, feldspar $(</=1.5 \mathrm{~cm}$ long) and biotite porphyritic, texture varies. \\
\hline 2003MBW11A & 429065 & 7265013 & Gabbro; gray-green, equigranular, $1-2 \mathrm{~mm}$ grains, $50 \%$ plagioclase, $50 \%$ mafics, minor quartz-carbonate veins. \\
\hline 2003MBW15A & 421633 & 7265354 & Siliceous dolomite; high silica content, very fine grained, very weak reaction to $\mathrm{HCl}$. \\
\hline 2003MBW42A & 433811 & 7265236 & Gabbro; white and green, medium grained, equigranular, $60-70 \%$ plagioclase, $30-40 \%$ mafics. \\
\hline 2003MBW53A & 434228 & 7266908 & Greenstone; dark green, very fine grained. \\
\hline 2003MBW87.2A & 433587 & 7268358 & Greenstone; forest green, aphanitic, highly magnetic. \\
\hline 2003MBW112A & 432727 & 7266592 & $\begin{array}{l}\text { Gabbro; medium green, fine-medium grained, equigranular, layered, } 50 \% \text { plagioclase, } 50 \% \text { mafics. Cut by numerous quartz }+ \text { epidote (?) } \\
\text { veins } 4 \mathrm{~mm} \text { wide. }\end{array}$ \\
\hline 2003MBW120A & 434931 & 7266137 & Mafic volcanic conglomerate/breccia greenstone; medium green, angular-subrounded clasts, range of clast sizes from $<1 \mathrm{~mm}$ to $7.5 \mathrm{~cm}$. \\
\hline 2003MBW240A & 433908 & 7268177 & Dolomite; pale tan, aphanitic, slowly effervescing, locally cut by quartz veins. \\
\hline 2003MBW249B & 428840 & 7267312 & Syenite; dark green, fine grained, equigranular. \\
\hline
\end{tabular}


Table 2. Location and description of rock samples collected for major-oxide, minor-oxide, and trace-element analyses in the Livengood Quadrangle.

\begin{tabular}{|c|c|c|c|}
\hline SAMPLE & UTM E & UTM N & DESCRIPTION \\
\hline 2003MBW258A & 429127 & 7266588 & Quartz syenite; porphyritic. \\
\hline 2003RN53A & 431130 & 7268846 & Greenstone; very dark green, very fine grained. \\
\hline 2003RN121A & 430070 & 7265879 & Quartz syenite; medium grained, $25 \%$ biotite and $75 \%$ feldspar phenocrysts, few porphyritic feldspar $1 \mathrm{~cm}$ long. \\
\hline 2003RN130A & 431660 & 7265410 & Greenstone; medium-pale green, massive. \\
\hline 2003RN209A & 441636 & 7265377 & Greenstone; gray-green, massive, conglomeratic texture (1-2 cm clasts, subrounded, clast-supported). \\
\hline $2003 Z 32 A$ & 433023 & 7275793 & Siliceous siltstone; pale to olive green, blocky to platy breaking. \\
\hline $2003 Z 60 A$ & 423239 & 7266166 & Greenstone; granular texture, blocky breaking. \\
\hline $2003 Z 74 A$ & 429742 & 7267713 & Siliceous dolomite; light tan to gray, high silica content, popcorn weathering surface. \\
\hline $2003 Z 78 A$ & 429498 & 7268163 & Greenstone; dark green to black, granular, massive to blocky. Carbonate veinlets 1-3 mm wide. \\
\hline $2003 Z 135 A$ & 430458 & 7272193 & Siliceous limestone; dark gray and white, silica as veins and weblike throughout rock. \\
\hline $2003 Z 142 \mathrm{~A}$ & 419355 & 7278817 & Hornblende diorite; green, medium grained $(2-3 \mathrm{~mm}), 60 \%$ plagiclase, $10 \%$ hornblende. \\
\hline 2003Z149B & 438713 & 7265890 & Biotite hornblende gabbro; pale to medium green, coarse grained, mostly equigranular, biotite as clots. \\
\hline $2003 Z 175 B$ & 440367 & 7265896 & Intermediate volcanic; pale to gray green, fine grained, sucratic texture. \\
\hline $2003 Z 175 \mathrm{C}$ & 440367 & 7265896 & Intermediate volcanic; pale green and white, fine grained, platy breaking. \\
\hline $2003 Z 185 A$ & 441101 & 7265636 & Mafic volcanic? olive green to green-black, very fine grained, trace pyrite. \\
\hline $2003 Z 211 C$ & 429098 & 7268767 & Syenite dike; dark gray, biotite porphyritic. \\
\hline $2003 Z 212 A$ & 429024 & 7268667 & Greenstone; amydgaloidal to microgabbroic to diabasic texture. \\
\hline $2003 Z 217 A$ & 428268 & 7270526 & $\begin{array}{l}\text { Limestone; dark gray, fine-medium grained, strong reaction to } \mathrm{HCl} \text {, some vuggy webwork of calcite veinlets }(<1 \mathrm{~mm} \text { wide veinlets, some } \\
\text { sparry grains). }\end{array}$ \\
\hline $2003 Z 218 A$ & 428304 & 7270489 & Greenstone; amygdaloidal (carbonate-filled), massive, somewhat granular. \\
\hline $2003 Z 239 A$ & 429297 & 7266656 & Granite; dark gray to black, porphyritic feldspar $1-2 \mathrm{~mm}$ long, iron oxide stained. \\
\hline $2003 Z 255 A$ & 427758 & 7266231 & Gabbro; black and white, fine grained, $1 \%$ disseminated pyrite and trace chalcopyrite (?). \\
\hline
\end{tabular}


Table 3. Concentration of trace elements in rock samples collected in the Livengood Quadrangle.

Note: --- = not analyzed.

\begin{tabular}{|c|c|c|c|c|c|c|c|c|c|c|c|c|c|c|c|c|c|c|c|c|}
\hline SAMPLE & $\begin{array}{l}\text { Au1 } \\
\text { ppm }\end{array}$ & $\begin{array}{l}\text { Au2 } \\
\mathrm{ppm}\end{array}$ & $\begin{array}{l}\text { Au3 } \\
\text { ppm }\end{array}$ & $\begin{array}{c}\mathrm{Pt} \\
\mathrm{ppm}\end{array}$ & $\begin{array}{c}\mathrm{Pd} \\
\mathrm{ppm}\end{array}$ & $\begin{array}{c}\mathrm{Ag} \\
\mathrm{ppm}\end{array}$ & $\begin{array}{l}\text { Al } \\
\% \\
\end{array}$ & $\begin{array}{l}\text { As1 } \\
\text { ppm }\end{array}$ & $\begin{array}{c}\text { As2 } \\
\% \\
\end{array}$ & $\begin{array}{c}\mathrm{Ba} \\
\mathrm{ppm}\end{array}$ & $\begin{array}{c}\mathrm{Be} \\
\mathrm{ppm}\end{array}$ & $\begin{array}{c}\mathrm{Bi} \\
\mathrm{ppm}\end{array}$ & $\begin{array}{c}\mathrm{Ca} \\
\% \\
\end{array}$ & $\begin{array}{c}\mathrm{Cd} \\
\mathrm{ppm}\end{array}$ & $\begin{array}{c}\text { Co } \\
\mathrm{ppm}\end{array}$ & $\begin{array}{c}\mathrm{Cr} \\
\mathrm{ppm}\end{array}$ & $\begin{array}{c}\mathrm{Cu} \\
\mathrm{ppm}\end{array}$ & $\begin{array}{l}\mathrm{Fe} \\
\% \\
\end{array}$ & $\begin{array}{c}\mathrm{Hg} \\
\mathrm{ppm}\end{array}$ & $\begin{array}{l}\mathrm{K} \\
\% \\
\end{array}$ \\
\hline 2001MBW449A & 0.046 & -- & -- & --- & -- & $<0.5$ & 6.27 & 182 & -- & 490 & 0.8 & $<2$ & 0.05 & $<0.5$ & 1 & 24 & \begin{tabular}{|r|}
6 \\
\end{tabular} & 0.80 & 0.03 & 0.30 \\
\hline 2001MBW450A & 0.306 & --- & -- & -- & -- & 0.5 & 6.82 & 309 & -- & 350 & 1.7 & $<2$ & 0.04 & 0.5 & $<1$ & 19 & 9 & 1.78 & 0.05 & 2.47 \\
\hline 2001MBW456A & 0.228 & --- & -- & --- & -- & $<0.5$ & 7.84 & 2640 & -- & 850 & 2.8 & $<2$ & 0.03 & $<0.5$ & $<1$ & 12 & 9 & 1.23 & 0.05 & 1.28 \\
\hline 2001MBW456B & 0.145 & -- & -- & -- & -- & $<0.5$ & 0.46 & 1955 & -- & 40 & $<0.5$ & $<2$ & 9.29 & $<0.5$ & 45 & 1260 & 28 & 3.04 & 0.01 & 0.08 \\
\hline 2001MBW457A & 0.676 & -- & -- & -- & -- & 1.9 & 7.57 & $>10000$ & 2.44 & 80 & 5.3 & $<2$ & 0.33 & 0.9 & 4 & 36 & 24 & 4.71 & 3.90 & 2.34 \\
\hline 2001MBW458A & $>10.0$ & -- & 34.7 & -- & -- & 9.2 & 0.81 & $>10000$ & 26.4 & 10 & 0.8 & 32 & 1.52 & 16.8 & 36 & 300 & 57 & 19.10 & 0.31 & 0.31 \\
\hline 2003JEA36A & 0.009 & --- & -- & --- & -- & $<0.5$ & 6.66 & 54 & -- & 60 & 0.5 & $<2$ & 4.10 & $<0.5$ & 43 & 94 & 50 & 8.51 & --- & 0.06 \\
\hline 2003JEA131A & $<0.005$ & -- & -- & -- & -- & $<0.5$ & 0.59 & 65 & -- & 120 & 0.7 & 2 & 0.21 & 10.7 & 84 & 102 & 472 & 8.04 & -- & 0.09 \\
\hline 2003JEA137A & $<0.005$ & -- & -- & -- & -- & $<0.5$ & 0.44 & $<5$ & -- & 190 & $<0.5$ & $<2$ & 0.01 & $<0.5$ & 1 & 136 & 9 & 0.42 & -- & 0.08 \\
\hline 2003JEA144A & $<0.005$ & -- & -- & --- & -- & $<0.5$ & 0.50 & $<5$ & -- & 50 & $<0.5$ & $<2$ & 0.01 & $<0.5$ & 3 & 83 & 25 & 0.74 & -- & 0.03 \\
\hline 2003JEA208A & -- & 0.007 & -- & 0.0010 & 0.004 & $<0.5$ & 8.47 & 5 & -- & 100 & $<0.5$ & $<2$ & 6.25 & $<0.5$ & 44 & 156 & 48 & 7.34 & -- & 0.04 \\
\hline 2003JEA256A & 0.023 & -- & -- & -- & -- & $<0.5$ & 1.37 & 466 & -- & 140 & 0.5 & $<2$ & 0.01 & $<0.5$ & 1 & 106 & 114 & 3.92 & 0.16 & 0.51 \\
\hline 2003JEA259A & -- & 0.102 & -- & 0.0032 & 0.001 & $<0.5$ & 0.45 & 413 & -- & 50 & $<0.5$ & $<2$ & 0.06 & $<0.5$ & 60 & 1045 & 10 & 3.75 & 0.17 & 0.03 \\
\hline 2003JEA263A & $<0.005$ & -- & --- & -- & -- & $<0.5$ & 0.78 & 14 & -- & 320 & $<0.5$ & 2 & 0.21 & $<0.5$ & 4 & 99 & 23 & 1.10 & -- & 0.11 \\
\hline 2003JEA264A & $<0.005$ & -- & -- & --- & -- & $<0.5$ & 0.11 & 6 & -- & 130 & $<0.5$ & 2 & 0.09 & $<0.5$ & 2 & 82 & 12 & 0.21 & -- & 0.02 \\
\hline 2003MBW5C & 4.01 & -- & -- & -- & -- & $<0.5$ & 0.49 & $>10000$ & 16.4 & 50 & 0.5 & 2 & 0.21 & 6.5 & 11 & 84 & 402 & 11.95 & 0.12 & 0.21 \\
\hline 2003MBW7A & 0.017 & --- & --- & -- & -- & $<0.5$ & 0.85 & 90 & -- & 90 & $<0.5$ & $<2$ & 0.01 & $<0.5$ & 2 & 81 & 10 & 0.42 & 0.02 & 0.35 \\
\hline 2003MBW9A & 2.16 & --- & --- & -- & -- & $<0.5$ & 7.64 & $>10000$ & 6.15 & 230 & 5.6 & $<2$ & 0.04 & $<0.5$ & 4 & 34 & 222 & 3.98 & 0.08 & 0.58 \\
\hline 2003MBW18C & 0.007 & -- & -- & -- & -- & $<0.5$ & 1.00 & 311 & -- & 1020 & 0.7 & $<2$ & 0.04 & 6.4 & 14 & 128 & 164 & 15.40 & -- & 0.26 \\
\hline 2003MBW31A & 0.029 & -- & -- & -- & -- & 0.6 & 0.96 & 320 & -- & 3010 & $<0.5$ & $<2$ & 0.06 & 2.6 & 9 & 164 & 381 & 11.50 & 0.12 & 0.18 \\
\hline 2003MBW64A & 0.005 & -- & -- & -- & -- & $<0.5$ & 0.51 & 180 & -- & 60 & $<0.5$ & $<2$ & 0.04 & $<0.5$ & 4 & 152 & 20 & 0.80 & -- & 0.04 \\
\hline 2003MBW65A & $<0.005$ & --- & -- & -- & -- & $<0.5$ & 0.34 & 72 & -- & 80 & $<0.5$ & $<2$ & 0.09 & $<0.5$ & 5 & 132 & 12 & 0.45 & -- & 0.05 \\
\hline 2003MBW66A & $<0.005$ & --- & -- & -- & -- & $<0.5$ & 0.06 & 10 & -- & 40 & $<0.5$ & $<2$ & 11.70 & $<0.5$ & 1 & 32 & 5 & 0.12 & -- & 0.01 \\
\hline 2003MBW74A & --- & 0.013 & -- & 0.0069 & 0.01 & $<0.5$ & 8.52 & $<5$ & -- & 340 & $<0.5$ & $<2$ & 6.06 & $<0.5$ & 33 & 35 & 162 & 8.95 & 0.01 & 0.17 \\
\hline 2003MBW79A & 0.029 & -- & -- & -- & -- & $<0.5$ & 1.32 & 154 & -- & 160 & $<0.5$ & $<2$ & 0.05 & $<0.5$ & 6 & 132 & 37 & 4.00 & 0.12 & 0.59 \\
\hline 2003MBW107B & 0.446 & -- & --- & -- & -- & $<0.5$ & 0.16 & 30 & -- & 30 & $<0.5$ & $<2$ & 0.01 & $<0.5$ & 1 & 112 & 18 & 0.36 & 0.02 & 0.04 \\
\hline 2003MBW109A & 0.023 & -- & --- & -- & -- & $<0.5$ & 1.45 & 239 & -- & 70 & 2.0 & $<2$ & 0.02 & $<0.5$ & 2 & 120 & 84 & 3.35 & 0.05 & 0.37 \\
\hline 2003MBW109D & 0.369 & -- & -- & -- & -- & 1.7 & 7.94 & 3070 & -- & 540 & 1.4 & $<2$ & 0.10 & 1.0 & 4 & 15 & 75 & 3.67 & 0.94 & 0.06 \\
\hline 2003MBW110A & 1.500 & -- & -- & -- & -- & $<0.5$ & 7.13 & $>10000$ & 6.97 & 4440 & 2.0 & $<2$ & 0.07 & 0.5 & 1 & 19 & 333 & 5.11 & 0.02 & 3.97 \\
\hline 2003MBW178B & $<0.005$ & -- & -- & -- & -- & $<0.5$ & 1.90 & 343 & -- & 190 & 1.4 & $<2$ & 0.01 & 0.7 & 22 & 128 & 132 & 6.79 & --- & 0.66 \\
\hline 2003MBW246A & --- & 0.001 & -- & 0.0043 & 0.004 & $<0.5$ & 0.46 & 12 & -- & 10 & $<0.5$ & $<2$ & 1.30 & $<0.5$ & 89 & 1230 & 19 & 4.62 & -- & 0.01 \\
\hline 2003MBW251A & 0.068 & -- & -- & -- & -- & $<0.5$ & 6.49 & 221 & -- & 570 & 1.0 & $<2$ & 0.03 & $<0.5$ & 1 & 55 & 25 & 0.99 & 0.06 & 0.93 \\
\hline 2003MBW255A & 0.481 & -- & -- & -- & -- & $<0.5$ & 5.72 & 4520 & -- & 160 & 1.8 & $<2$ & 0.02 & $<0.5$ & 1 & 52 & 32 & 3.40 & 0.05 & 2.55 \\
\hline 2003MBW256A(1) & 0.553 & --- & -- & -- & -- & $<0.5$ & 6.36 & 3320 & -- & 200 & 7.7 & $<2$ & 0.03 & 1.6 & 1 & 36 & 27 & 2.93 & 0.02 & 2.97 \\
\hline 2003MBW256A(2) & 1.060 & -- & -- & -- & -- & $<0.5$ & 7.66 & 805 & -- & 410 & 2.4 & $<2$ & 0.09 & $<0.5$ & $<1$ & 36 & 4 & 1.30 & 0.04 & 2.34 \\
\hline 2003MBW259A & $<0.005$ & -- & -- & -- & -- & $<0.5$ & 6.99 & 95 & -- & 540 & 4.6 & $<2$ & 0.01 & $<0.5$ & $<1$ & 17 & 6 & 2.93 & -- & 3.89 \\
\hline 2003MBW261A & $<0.005$ & --- & --- & --- & --- & $<0.5$ & 6.06 & 39 & -- & 1030 & 6.1 & $<2$ & 0.02 & $<0.5$ & $<1$ & 35 & 9 & 5.77 & -- & 2.80 \\
\hline 2003MBW262A & 0.036 & --- & -- & -- & -- & $<0.5$ & 8.04 & 1335 & -- & 1240 & 1.4 & $<2$ & 0.03 & $<0.5$ & 1 & 37 & 8 & 2.26 & 0.06 & 3.69 \\
\hline 2003MBW267A & 0.014 & -- & --- & --- & -- & $<0.5$ & 8.32 & 664 & -- & 2170 & 2.2 & $<2$ & 0.01 & $<0.5$ & $<1$ & 34 & 4 & 0.79 & 0.03 & 5.39 \\
\hline 2003MBW269A & 0.196 & -- & -- & -- & -- & 0.7 & 7.52 & 4340 & -- & 450 & 0.8 & $<2$ & 0.01 & $<0.5$ & $<1$ & 46 & 13 & 2.17 & 0.16 & 0.13 \\
\hline
\end{tabular}


Table 3. Concentration of trace elements in rock samples collected in the Livengood Quadrangle.

Note: --- $=$ not analyzed.

\begin{tabular}{|c|c|c|c|c|c|c|c|c|c|c|c|c|c|c|}
\hline SAMPLE & $\begin{array}{c}\mathrm{Mg} \\
\% \\
\end{array}$ & $\begin{array}{c}\mathrm{Mn} \\
\mathrm{ppm}\end{array}$ & $\begin{array}{c}\text { Mo } \\
\text { ppm }\end{array}$ & $\begin{array}{c}\mathrm{Na} \\
\%\end{array}$ & $\begin{array}{c}\mathrm{Ni} \\
\mathrm{ppm}\end{array}$ & $\begin{array}{c}\mathrm{P} \\
\mathrm{ppm}\end{array}$ & $\begin{array}{c}\mathrm{Pb} \\
\mathrm{ppm}\end{array}$ & $\begin{array}{l}\mathrm{S} \\
\% \\
\end{array}$ & $\begin{array}{c}\mathrm{Sb} \\
\mathrm{ppm}\end{array}$ & $\begin{array}{c}\mathrm{Sr} \\
\mathrm{ppm}\end{array}$ & $\begin{array}{l}\mathrm{Ti} \\
\% \\
\end{array}$ & $\begin{array}{c}\mathrm{V} \\
\mathrm{ppm}\end{array}$ & $\begin{array}{c}\text { W } \\
\text { ppm }\end{array}$ & $\begin{array}{c}\mathrm{Zn} \\
\mathrm{ppm}\end{array}$ \\
\hline 2001MBW449A & 0.02 & 31 & 11 & 4.52 & 4 & 420 & 24 & 0.20 & 21 & 257 & 0.27 & 2 & $<10$ & 9 \\
\hline 2001MBW450A & 0.07 & 25 & 3 & 3.33 & 3 & 260 & 35 & 0.60 & 31 & 286 & 0.17 & 5 & $<10$ & 27 \\
\hline 2001MBW456A & 0.07 & 36 & 3 & 4.35 & 2 & 680 & 20 & 0.25 & 37 & 94 & 0.27 & 11 & 10 & 18 \\
\hline 2001MBW456B & 6.90 & 1000 & $<1$ & 0.08 & 1055 & 30 & 6 & 0.44 & 14 & 608 & 0.01 & 13 & $<10$ & 249 \\
\hline 2001MBW457A & 0.24 & 48 & $<1$ & 3.41 & 30 & 1170 & 16 & 1.70 & 95 & 1005 & 0.23 & 134 & 40 & 70 \\
\hline 2001MBW458A & 1.01 & 265 & 6 & 0.03 & 219 & 300 & 2800 & 6.60 & 461 & 505 & 0.01 & 24 & 50 & 93 \\
\hline 2003JEA36A & 3.28 & 1455 & $<1$ & 3.00 & 64 & 670 & 3 & 0.11 & 8 & 194 & 1.03 & 370 & $<10$ & 110 \\
\hline 2003JEA131A & 0.05 & 6400 & 5 & 0.01 & 124 & 5230 & $<2$ & 0.01 & 8 & 19 & 0.01 & 101 & $<10$ & 648 \\
\hline 2003JEA137A & 0.02 & 56 & 1 & 0.02 & 6 & 80 & $<2$ & $<0.01$ & $<5$ & 12 & 0.02 & 5 & $<10$ & 6 \\
\hline 2003JEA144A & 0.03 & 98 & 4 & 0.01 & 8 & 140 & $<2$ & $<0.01$ & $<5$ & 3 & 0.01 & 14 & $<10$ & 10 \\
\hline 2003JEA208A & 5.24 & 1265 & 4 & 3.06 & 96 & 340 & 3 & 0.06 & 8 & 56 & 0.65 & 279 & $<10$ & 60 \\
\hline 2003JEA256A & 0.14 & 45 & 8 & 0.01 & 15 & 530 & 3 & 0.01 & 8 & 11 & 0.04 & 44 & $<10$ & 75 \\
\hline 2003JEA259A & 12.30 & 593 & 2 & 0.01 & 1225 & 50 & $<2$ & 0.04 & 114 & 25 & 0.01 & 28 & $<10$ & 53 \\
\hline 2003JEA263A & 0.08 & 154 & 1 & 0.04 & 18 & 1020 & 3 & $<0.01$ & $<5$ & 21 & 0.04 & 59 & $<10$ & 19 \\
\hline 2003JEA264A & 0.02 & 18 & 4 & $<0.01$ & 7 & 200 & $<2$ & $<0.01$ & $<5$ & 11. & $<0.01$ & 10 & $<10$ & 6 \\
\hline 2003MBW5C & 0.05 & 392 & 6 & 0.01 & 7 & 480 & 17 & 3.65 & 201 & 294 & 0.01 & 58 & $<10$ & 56 \\
\hline 2003MBW7A & 0.07 & 34 & $<1$ & 0.01 & 6 & 50 & 2 & 0.01 & $<5$ & 8 & 0.03 & 24 & $<10$ & 7 \\
\hline 2003MBW9A & 0.05 & 84 & 13 & 4.65 & 3 & 2280 & 12 & 0.85 & 39 & 461 & 0.16 & 110 & 50 & 33 \\
\hline 2003MBW18C & 0.19 & 312 & 13 & 0.06 & 180 & 4210 & $<2$ & 0.01 & 47 & 23 & 0.04 & 59 & $<10$ & 783 \\
\hline 2003MBW31A & 0.06 & 699 & 9 & 0.02 & 102 & 5890 & 4 & 0.06 & 13 & 49 & 0.05 & 241 & $<10$ & 516 \\
\hline 2003MBW64A & 0.05 & 41 & 5 & 0.01 & 54 & 160 & $<2$ & $<0.01$ & $<5$ & 5 & 0.05 & 23 & $<10$ & 17 \\
\hline 2003MBW65A & 0.02 & 130 & 3 & 0.01 & 20 & 80 & 2 & $<0.01$ & $<5$ & 5 & 0.03 & 12 & $<10$ & 10 \\
\hline 2003MBW66A & 2.23 & 58 & $<1$ & $<0.01$ & 4 & 110 & $<2$ & $<0.01$ & $<5$ & 79 & $<0.01$ & 2 & $<10$ & 4 \\
\hline 2003MBW74A & 2.92 & 1575 & $<1$ & 4.01 & 24 & 410 & 2 & 0.01 & $<5$ & 442 & 0.47 & 359 & $<10$ & 100 \\
\hline 2003MBW79A & 0.13 & 170 & 6 & 0.01 & 31 & 840 & 7 & 0.01 & 8 & 5 & 0.05 & 201 & $<10$ & 160 \\
\hline 2003MBW107B & 0.01 & 21 & 4 & $<0.01$ & 6 & 70 & $<2$ & $<0.01$ & $<5$ & 19 & 0.01 & 9 & $<10$ & 6 \\
\hline 2003MBW109A & 0.10 & 60 & 5 & 0.01 & 25 & 680 & $<2$ & 0.01 & 17 & 6 & 0.05 & 92 & $<10$ & 218 \\
\hline 2003MBW109D & 0.02 & 193 & 2 & 0.01 & 5 & 870 & 16 & $<0.01$ & 8 & 53 & 0.32 & 97 & 30 & 28 \\
\hline 2003MBW110A & 0.07 & 55 & $<1$ & 0.16 & 3 & 1840 & 4 & 0.04 & 5 & 469 & 0.11 & 107 & 10 & 41 \\
\hline 2003MBW178B & 0.11 & 2270 & 5 & 0.02 & 48 & 1060 & $<2$ & $<0.01$ & 6 & 45 & 0.06 & 39 & $<10$ & 112 \\
\hline 2003MBW246A & $>15.0$ & 743 & $<1$ & 0.01 & 1830 & $<10$ & $<2$ & $<0.01$ & 5 & 26 & 0.01 & 27 & $<10$ & 44 \\
\hline 2003MBW251A & 0.03 & 23 & 1 & 4.12 & 4 & 160 & 28 & 0.34 & 29 & 103 & 0.20 & 3 & $<10$ & 20 \\
\hline 2003MBW255A & 0.04 & 42 & 4 & 2.64 & 4 & 440 & 54 & 1.63 & 19 & 424 & 0.10 & 6 & $<10$ & 24 \\
\hline 2003MBW256A(1) & 0.24 & 37 & $<1$ & 0.49 & 3 & 140 & 31 & 2.37 & 365 & 72 & 0.17 & 3 & $<10$ & 41 \\
\hline 2003MBW256A(2) & 0.08 & 37 & 3 & 3.42 & 2 & 330 & 22 & 1.06 & 58 & 172 & 0.23 & 3 & $<10$ & 8 \\
\hline 2003MBW259A & 0.65 & 18 & 28 & 0.04 & 1 & 150 & 23 & 1.06 & 21 & 31 & 0.09 & 13 & $<10$ & 19 \\
\hline 2003MBW261A & 0.23 & 37 & 2 & 0.92 & 3 & 120 & 30 & 0.20 & 24 & 49 & 0.16 & 6 & $<10$ & 150 \\
\hline 2003MBW262A & 0.03 & 9 & 2 & 3.97 & 1 & 530 & 45 & 0.86 & 45 & 140 & 0.27 & 3 & $<10$ & 18 \\
\hline 2003MBW267A & 0.07 & 13 & $<1$ & 2.39 & 3 & 160 & 29 & 0.26 & 21 & 91 & 0.27 & 1 & $<10$ & 13 \\
\hline 2003MBW269A & 0.01 & 42 & 4 & 6.32 & 3 & 520 & 265 & 0.44 & 129 & 416 & 0.28 & 12 & $<10$ & 76 \\
\hline
\end{tabular}


Table 3. Concentration of trace elements in rock samples collected in the Livengood Quadrangle.

Note: --- = not analyzed.

\begin{tabular}{|c|c|c|c|c|c|c|c|c|c|c|c|c|c|c|c|c|c|c|c|c|}
\hline SAMPLE & Au1 & Au2 & Au3 & $\mathrm{Pt}$ & $\mathrm{Pd}$ & $\mathrm{Ag}$ & $\mathrm{Al}$ & As1 & As2 & $\mathrm{Ba}$ & $\mathrm{Be}$ & $\mathrm{Bi}$ & $\mathrm{Ca}$ & $\mathrm{Cd}$ & Co & $\mathrm{Cr}$ & $\mathrm{Cu}$ & $\mathrm{Fe}$ & $\mathrm{Hg}$ & K \\
\hline 2003MBW279D & 0.007 & --- & -- & -- & -- & $<0.5$ & 1.64 & 65 & -- & 110 & $<0.5$ & $<2$ & 0.43 & $<0.5$ & 3 & 108 & 6 & 0.95 & -- & 0.16 \\
\hline 2003RN113A & 0.010 & --- & --- & --- & - & $<0.5$ & 0.76 & 82 & --- & 60 & 0.5 & $<2$ & 0.01 & $<0.5$ & 1 & 178 & 52 & 3.64 & 0.25 & 0.33 \\
\hline 2003RN149A & 0.006 & -- & -- & -- & -- & $<0.5$ & 0.83 & 50 & -- & 390 & 1.3 & 2 & 0.01 & 1.0 & 163 & 154 & 184 & 4.70 & --- & 0.27 \\
\hline 2003RN196A & $<0.005$ & --- & --- & --- & -- & $<0.5$ & 0.81 & 56 & -- & 160 & $<0.5$ & $<2$ & 0.01 & $<0.5$ & 7 & 160 & 15 & 1.42 & --- & 0.30 \\
\hline $2003 Z 34 A$ & 0.020 & --- & --- & --- & --- & $<0.5$ & 3.34 & 244 & --- & 2430 & 1.1 & $<2$ & 0.13 & 0.8 & 8 & 116 & 133 & 6.43 & 0.26 & 1.18 \\
\hline $2003 Z 70 \mathrm{C}$ & 0.017 & -- & -- & -- & -- & $<0.5$ & 0.68 & 62 & -- & 190 & $<0.5$ & $<2$ & 0.01 & 0.5 & 3 & 192 & 87 & 4.16 & 0.32 & 0.23 \\
\hline $2003 Z 73 A$ & --- & 0.003 & -- & 0.0071 & 0.006 & $<0.5$ & 0.28 & 6 & -- & 20 & $<0.5$ & $<2$ & 0.17 & $<0.5$ & 75 & 1300 & 16 & 4.50 & -- & $<0.01$ \\
\hline 2003Z87A & --- & 0.001 & -- & 0.0046 & 0.004 & $<0.5$ & 0.46 & 7 & -- & 30 & $<0.5$ & $<2$ & 0.38 & $<0.5$ & 85 & 1430 & 15 & 4.81 & -- & 0.01 \\
\hline 2003Z91A & -- & 0.003 & -- & 0.0052 & 0.005 & $<0.5$ & 0.62 & 79 & -- & 30 & $<0.5$ & $<2$ & 17.80 & $<0.5$ & 75 & 1215 & 16 & 4.96 & -- & 0.02 \\
\hline 2003Z109B & 0.007 & -- & -- & --- & -- & $<0.5$ & 1.32 & 38 & -- & 4920 & 0.8 & $<2$ & 0.04 & $<0.5$ & 1 & 138 & 22 & 3.54 & -- & 0.28 \\
\hline 2003Z157B & $<0.005$ & -- & --- & --- & -- & $<0.5$ & 0.73 & 17 & -- & 180 & $<0.5$ & $<2$ & $<0.01$ & $<0.5$ & $<1$ & 110 & 28 & 2.12 & -- & 0.27 \\
\hline 2003Z161B & $<0.005$ & -- & -- & --- & -- & $<0.5$ & 0.79 & 33 & -- & 100 & 0.5 & $<2$ & 0.01 & $<0.5$ & 1 & 155 & 73 & 3.43 & -- & 0.28 \\
\hline 2003Z167B & $<0.005$ & --- & $-{ }_{-1}$ & --- & $-{ }_{-1}$ & $<0.5$ & 0.58 & 8 & --- & 160 & $<0.5$ & $<2$ & 0.01 & $<0.5$ & 2 & 187 & 17 & 1.24 & $-{ }_{-1}$ & 0.18 \\
\hline 2003Z178B & 0.005 & -- & --- & --- & -- & $<0.5$ & 7.01 & $<5$ & -- & 20 & $<0.5$ & $<2$ & 15.45 & $<0.5$ & 28 & 49 & 265 & 7.58 & --- & 0.01 \\
\hline 2003Z198A & 0.010 & -- & -- & --- & -- & $<0.5$ & 0.89 & 27 & -- & 6550 & 0.5 & $<2$ & 0.07 & 0.5 & 1 & 178 & 122 & 2.38 & 0.06 & 0.15 \\
\hline 2003Z214B & 0.006 & --- & --- & --- & --- & $<0.5$ & 0.04 & 295 & --- & 50 & $<0.5$ & $<2$ & 0.18 & $<0.5$ & 1 & 130 & 5 & 4.71 & --- & 0.01 \\
\hline 2003Z239B & $<0.005$ & -- & -- & -- & -- & 0.5 & 1.56 & 102 & -- & 180 & $<0.5$ & $<2$ & 2.21 & $<0.5$ & 13 & 79 & 7 & 2.55 & -- & 0.24 \\
\hline $2003 Z 243 A$ & 0.045 & -- & -- & --- & -- & 0.5 & 4.03 & 938 & -- & 1390 & 2.7 & $<2$ & 4.13 & $<0.5$ & 26 & 494 & 22 & 5.07 & 0.02 & 2.37 \\
\hline $2003 Z 244 A$ & 2.91 & --- & -- & --- & -- & 5.9 & 4.48 & $>10000$ & 2.11 & 790 & 5.2 & 2 & 2.94 & 13.8 & 9 & 88 & 23 & 4.53 & 0.31 & 4.61 \\
\hline $2003 Z 248 A$ & $<0.005$ & -- & --- & --- & -- & $<0.5$ & 0.42 & 170 & -- & 30 & $<0.5$ & $<2$ & 2.46 & $<0.5$ & 48 & 923 & 12 & 3.77 & --- & 0.02 \\
\hline $2003 Z 255 A$ & $<0.005$ & 0.003 & - & 0.0038 & 0.003 & $<0.5$ & 9.27 & 30 & --- & 100 & $<0.5$ & $<2$ & 5.78 & $<0.5$ & 30 & 41 & 152 & 7.78 & --- & 0.15 \\
\hline
\end{tabular}


Table 3. Concentration of trace elements in rock samples collected in the Livengood Quadrangle.

Note: --- = not analyzed

\begin{tabular}{|c|c|c|c|c|c|c|c|c|c|c|c|c|c|c|}
\hline SAMPLE & $\begin{array}{c}\mathrm{Mg} \\
\% \\
\end{array}$ & $\begin{array}{c}\mathrm{Mn} \\
\mathrm{ppm}\end{array}$ & $\begin{array}{c}\text { Mo } \\
\text { ppm }\end{array}$ & $\begin{array}{c}\mathrm{Na} \\
\%\end{array}$ & $\begin{array}{c}\mathrm{Ni} \\
\mathrm{ppm}\end{array}$ & $\begin{array}{c}\mathrm{P} \\
\mathrm{ppm}\end{array}$ & $\begin{array}{c}\mathrm{Pb} \\
\mathrm{ppm}\end{array}$ & $\begin{array}{l}S \\
\% \\
\end{array}$ & $\begin{array}{c}\mathrm{Sb} \\
\mathrm{ppm}\end{array}$ & $\begin{array}{c}\mathrm{Sr} \\
\mathrm{ppm}\end{array}$ & $\begin{array}{l}\mathrm{Ti} \\
\% \\
\end{array}$ & $\begin{array}{c}\mathrm{V} \\
\mathrm{ppm}\end{array}$ & $\begin{array}{c}\text { W } \\
\mathrm{ppm}\end{array}$ & $\begin{array}{c}\mathrm{Zn} \\
\mathrm{ppm}\end{array}$ \\
\hline 2003MBW279D & 0.20 & 371 & 2 & 0.76 & 20 & 190 & 3 & 0.02 & $<5$ & 75 & 0.05 & 21 & $<10$ & 18 \\
\hline 2003RN113A & 0.08 & 29 & 21 & 0.03 & 7 & 2520 & 4 & 0.04 & 11 & 12 & 0.04 & 216 & $<10$ & 8 \\
\hline 2003RN149A & 0.02 & $>10000$ & 23 & 0.02 & 126 & 2190 & 2 & 0.01 & $<5$ & 22 & 0.02 & 26 & $<10$ & 161 \\
\hline 2003RN196A & 0.07 & 2860 & 6 & 0.01 & 12 & 470 & $<2$ & $<0.01$ & 5 & 18 & 0.04 & 18 & $<10$ & 16 \\
\hline 2003Z34A & 0.34 & 126 & 2 & 0.03 & 32 & 4420 & 11 & 0.07 & 15 & 55 & 0.15 & 187 & $<10$ & 90 \\
\hline $2003 Z 70 C$ & 0.05 & 124 & 11 & 0.02 & 31 & 980 & 4 & 0.01 & 28 & 11 & 0.02 & 90 & $<10$ & 106 \\
\hline $2003 Z 73 A$ & $>15.0$ & 942 & 1 & 0.02 & 1755 & 10 & $<2$ & 0.05 & 8 & 2 & $<0.01$ & 22 & $<10$ & 38 \\
\hline 2003Z87A & $>15.0$ & 750 & $<1$ & 0.01 & 1380 & 10 & $<2$ & 0.06 & 15 & 8 & 0.01 & 30 & $<10$ & 46 \\
\hline $2003 Z 91 A$ & 10.55 & 1155 & $<1$ & 0.01 & 1095 & 10 & $<2$ & 0.32 & 16 & 546 & 0.01 & 33 & $<10$ & 49 \\
\hline 2003Z109B & 0.10 & 24 & 7 & 0.02 & 9 & $>10000$ & 5 & 0.05 & 15 & 88 & 0.06 & 93 & $<10$ & 52 \\
\hline 2003Z157B & 0.05 & 8 & 3 & 0.01 & 3 & 770 & $<2$ & 0.01 & $<5$ & 5 & 0.03 & 54 & $<10$ & 5 \\
\hline 2003Z161B & 0.08 & 77 & 10 & 0.02 & 7 & 930 & 8 & 0.01 & 5 & 20 & 0.05 & 94 & $<10$ & \\
\hline 2003Z167B & 0.04 & 25 & 8 & 0.04 & 14 & 270 & $<2$ & $<0.01$ & $<5$ & 18 & 0.02 & 17 & $<10$ & 16 \\
\hline 2003Z178B & 6.26 & 1795 & $<1$ & 0.08 & 37 & 680 & 3 & 0.01 & 5 & 47 & 0.66 & 333 & $<10$ & 59 \\
\hline $2003 Z 198 A$ & 0.06 & 41 & 7 & $<0.01$ & 7 & 3710 & 5 & 0.01 & 44 & 96 & 0.03 & 116 & $<10$ & 59 \\
\hline $2003 Z 214 B$ & 0.06 & 29 & 10 & $<0.01$ & 11 & 100 & $<2$ & 4.40 & 132 & 2 & $<0.01$ & 6 & $<10$ & 15 \\
\hline 2003Z239B & 1.08 & 2810 & 5 & 0.64 & 25 & 290 & $<2$ & 0.01 & $<5$ & 238 & 0.03 & 30 & $<10$ & 31 \\
\hline $2003 Z 243 A$ & 8.30 & 1090 & $<1$ & 0.91 & 408 & 1280 & 16 & 0.17 & 12 & 704 & 0.16 & 91 & $<10$ & 71 \\
\hline $2003 Z 244 A$ & 2.69 & 712 & 2 & 0.20 & 144 & 530 & 2240 & 1.28 & 537 & 736 & 0.18 & 72 & $<10$ & 1745 \\
\hline $2003 Z 248 A$ & 14.55 & 677 & 16 & 0.01 & 949 & 40 & $<2$ & 0.01 & 8 & 54 & 0.01 & 28 & $<10$ & 46 \\
\hline $2003 Z 255 A$ & 2.89 & 1350 & $<1$ & 4.03 & 20 & 430 & $<2$ & 0.01 & $<5$ & 406 & 0.43 & 324 & $<10$ & 61 \\
\hline
\end{tabular}


Table 4. Location and description of rock samples collected for trace-element analysis in the Livengood Quadrangle.

\begin{tabular}{|c|c|c|c|}
\hline SAMPLE & UTME & UTM N & DESCRIPTION \\
\hline 2001MBW449A & 429241 & 7266677 & Intrusive; black, aphanitic groundmass; porphyritic, white feldspar phenocrysts. Possible hypabyssal monzonite plug or dike. \\
\hline 2001MBW450A & 429169 & 7266760 & Tan volcanic breccia cemented by black, aphanitic, siliceous material. Contains trace disseminated pyrite. \\
\hline 2001MBW456A & 428953 & 7266109 & $\begin{array}{l}\text { Porphyritic hypabyssal volcanic (?) float with gray, fine grained, aphanitic matrix. Veins of quartz and unknown black mineral in patches } \\
\text { and as crystals. }\end{array}$ \\
\hline 2001MBW456B & 428953 & 7266109 & Igneous (?) float is white-gray and fine grained with disseminated chalcopyrite $+/$ - pyrite and other sulfides. \\
\hline 2001MBW457A & 428856 & 7266091 & Altered porphyritic volcanic rock is gray with strong iron-oxide staining and disseminated pyrite and arsenopyrite. \\
\hline 2001MBW458A & 428820 & 7266075 & Brecciated vuggy veins of quartz and arsenopyrite, lesser pyrite. \\
\hline 2003JEA36A & 431297 & 7267388 & Igneous float; gray, siliceous, with disseminated sulfide, pyrite (and arsenopyrite?). \\
\hline 2003JEA131A & 440983 & 7269747 & Sandstone or altered mafic subcrop; red, punky weathered, limonite matrix, brecciated (?). \\
\hline 2003JEA137A & 431239 & 7274147 & Gray chert float with trace amounts of fine grained, gray sulfide. \\
\hline 2003JEA144A & 430009 & 7273478 & Orange-gray chert float with iron oxide and silica breccia, quartz in matrix is vuggy with drusy texture and webbing. \\
\hline 2003JEA208A & 438876 & 7266632 & Large boulders of greenstone, possible breccia or tuff with patches of finer grained material, trace sulfide. \\
\hline 2003JEA256A & 428134 & 7265603 & Aphanitic plutonic (?) rock with rare disseminated sulfide. Red weathering. \\
\hline 2003JEA259A & 429095 & 7265008 & Serpentinite with pervasive and strong alteration of quartz, carbonate, and iron oxide. \\
\hline 2003JEA263A & 425193 & 7265354 & Altered sample of siliceous dolomite float; weathers orange, honeycomb to vuggy texture after pyrite or carbonate. \\
\hline 2003JEA264A & 425159 & 7265310 & Amy Dolomite (?) float; weathers cream-orange, vuggy, slight gray color in places suggests arsenopyrite. \\
\hline 2003MBW5C & 428864 & 7266056 & Arsenopyrite and quartz coarsely intergrown. Arsenopyrite is massive and highly altered to scorodite. Quartz is milky and brecciated. \\
\hline 2003MBW7A & 428398 & 7265572 & $\begin{array}{l}\text { Silicious mudstone or silicified shale, surfaces are iron stained and locally cut by quartz and iron-oxide veins up to } 1 \mathrm{~cm} \text { wide. Open } \\
\text { fractures are also iron oxide stained. }\end{array}$ \\
\hline 2003MBW9A & 430052 & 7266066 & Igneous dike outcrop with arsenopyrite disseminated and as vein fill. \\
\hline 2003MBW18C & 433983 & 7273623 & Vuggy chert breccia cemented by brown bottle-glass limonite. \\
\hline 2003MBW31A & 433131 & 7272435 & Black chert breccia float cemented by dark brown, bottle-glass limonite. \\
\hline 2003MBW64A & 433854 & 7269447 & $\begin{array}{l}\text { Angular float at head of recent tailings. Light gray, granular, siliceous rock with rusty-orange iron staining. Brecciated, banded quartz } \\
\text { veins. }\end{array}$ \\
\hline 2003MBW65A & 433754 & 7269702 & Siliceous outcrop with iron-stained vugs. \\
\hline 2003MBW66A & 434399 & 7269902 & $\begin{array}{l}\text { Dolomite float, mostly pale gray and siliceous. Effervesces slowly. Cut by thin }</=1 \mathrm{~mm} \text { black unknown stringers. Patches of tan rhomb- } \\
\text { shaped clasts (?) (up to } 3 \mathrm{~mm} \text { in diameter) of possible dolomite in aphanitic, light gray matrix. }\end{array}$ \\
\hline 2003MBW74A & 431761 & 7265967 & $\begin{array}{l}\text { Gabbro is dark green, fine grained ( }</=1.5 \mathrm{~mm} \text { diameter crystals), equigranular, }+/ \text { - hornblende?, clinopyroxene, plagioclase }(30-50 \%) \text {, } \\
\text { mafics }(50-70 \%) \text {. Approximately } 1 \% \text { disseminated sulfide (either pyrite? or chalcopyrite?). }\end{array}$ \\
\hline 2003MBW79A & 433127 & 7267465 & Sheared, brecciated, +/- gossanous, +/- microveinlets of milky quartz, black, +/- iron-stained Amy unit silicified mudstone. \\
\hline 2003MBW107B & 433724 & 7267431 & Milky quartz vein $2.5 \mathrm{~cm}$ thick, crystalline, with open vugs. \\
\hline 2003MBW109A & 433733 & 7267630 & $\begin{array}{l}\text { Bright orange-brown gossanous rocks, either massive or brecciated fragments replaced by and cemented by iron oxides. Other samples } \\
\text { have bands and veins of limonite cutting them. Originally silicified mudstone/chert. }\end{array}$ \\
\hline 2003MBW109D & 433733 & 7267630 & White and brown siliceous rock with disseminated cubes ( $</=1.5 \mathrm{~mm}$ in diameter) of limonite (former pyrite). \\
\hline 2003MBW110A & 433688 & 7267650 & $\begin{array}{l}\text { Igneous dike (?); extensive clay altering gives white/cream color. Vugs, +/- possible feldspar phenocrysts up to } 2 \mathrm{~mm} \text { in diameter. } \\
\text { Green staining on some samples is possibly scorodite. }\end{array}$ \\
\hline 2003MBW178B & 440406 & 7273430 & Chert breccia with brown iron-oxide cement. Open fractures are stained with iron and manganese oxides. \\
\hline
\end{tabular}


Table 4. Location and description of rock samples collected for trace-element analysis in the Livengood Quadrangle.

\begin{tabular}{|c|c|c|c|}
\hline SAMPLE & UTME & UTM N & DESCRIPTION \\
\hline 2003MBW246A & 428870 & 7267459 & Serpentinite; very mottled where intensely altered. \\
\hline 2003MBW251A & 428969 & 7267187 & Felsic porphyritic dike; pale gray, granular matrix, open vugs (former mafics?), feldspar phenocrysts $3 \mathrm{~mm}$ long. \\
\hline 2003MBW255A & 429167 & 7266762 & Porphyritic dike; cut and brecciated by black aphanitic material with disseminated pyrite. Feldspar phenocrysts $4 \mathrm{~mm}$ long. \\
\hline 2003MBW256A & 429198 & 7266655 & Porphyritic dike or plug with dark gray matrix, white rectangular feldspar phenocrysts $5 \mathrm{~mm}$ long. \\
\hline 2003MBW259A & 429051 & 7266651 & Metasedimentary rock or dike; medium gray weathered surface. \\
\hline 2003MBW261A & 428955 & 7266634 & Porphyritic pluton or dike; gray-orange on the fresh surface, orange stained feldspar phenocrysts $5 \mathrm{~mm}$ long. \\
\hline 2003MBW262A & 428925 & 7266658 & Igneous float; aphanitic matrix, possible clear feldspar phenocrysts $=/<2 \mathrm{~mm}$, weathered surfaces show weak orange-yellow staining. \\
\hline 2003MBW267A & 428925 & 7266707 & Porphyry float with vein fill of micro-veinlets of crystalline quartz coated with limonite. \\
\hline 2003MBW269A & 429014 & 7266800 & Igneous subcrop; pale gray on the fresh surface, iron-oxide staining. \\
\hline 2003MBW279D & 429306 & 7266584 & Milky quartz veins with pyrite and secondary limonite in sedimentary rock. \\
\hline 2003RN113A & 438787 & 7273919 & Chert breccia; dark gray to black, iron-oxide stained, with perhaps $1-2 \%$ former pyrite. \\
\hline 2003RN149A & 432478 & 7276053 & Chert breccia; pale gray, iron-oxide cemented. \\
\hline 2003RN196A & 440972 & 7278040 & $\begin{array}{l}\text { Chert breccia; gray, abundant iron- and manganese-stains. Scattered quartz veinlets are randomly oriented. Local boulders } 1 \mathrm{~m} \text { cubed } \\
\text { are abundantly iron- and manganese-oxide stained. }\end{array}$ \\
\hline $2003 Z 34 A$ & 432956 & 7275452 & Chert pebble breccia with orange, brown, and black iron-oxide staining. Some vugs present in matrix. \\
\hline $2003 Z 70 \mathrm{C}$ & 430365 & 7267888 & Siltstone with abundant boxworks, lined with orange and brown iron-oxide stains. \\
\hline 2003Z73A & 429889 & 7267665 & $\begin{array}{l}\text { Serpentinite; strongly silica-carbonate altered samples have stronger magnetic readings, trace }(1 \%) \text { disseminated sulfides are oxidized to } \\
\text { limonite. Also dark gray to black sulfide clots forming discontinuous bands. }\end{array}$ \\
\hline 2003Z87A & 429230 & 7267470 & $\begin{array}{l}\text { Serpentinite with trace amounts of disseminated pyrite in some samples. Minor quartz, }+/ \text { - ankerite veinlets } 2-3 \mathrm{~mm} \text {. Moderate silica- } \\
\text { carbonate alteration. }\end{array}$ \\
\hline 2003Z91A & 429087 & 7267167 & $\begin{array}{l}\text { Serpentinite with orange and black, silica-carbonate altered surfaces and minor, green fuchsite. } 1-2 \% \text { fine grained, disseminated pyrite } \\
\text { mostly }</=1 \mathrm{~mm} \text { across, but several grains up to } 2 \mathrm{~mm} \text { across. }\end{array}$ \\
\hline $2003 Z 109 B$ & 429994 & 7272298 & Chert breccia with yellow to orange limonite cement. \\
\hline $2003 Z 157 B$ & 442125 & 7267825 & Chert breccia; tan in color, with heavy iron-oxide orange coating and orange limonite cement. \\
\hline $2003 Z 161 \mathrm{~B}$ & 421437 & 7269546 & Chert; dark gray, highly fractured with orange-brown limonite on surfaces. \\
\hline $2003 Z 167 A$ & 420358 & 7270605 & Chert; highly limonite stained to orange and black. \\
\hline 2003Z178B & 440375 & 7265549 & $\begin{array}{l}\text { Intermediate volcanic rock; gray to pale green-gray, fine grained. Fracture surfaces are commonly partially coated with manganese-oxide } \\
\text { dendrites. Several fracture surfaces partially coated with bright green malachite and/or chrysocolla? }\end{array}$ \\
\hline $2003 Z 198 \mathrm{~A}$ & 431249 & 7272532 & Siliceous mudstone; iron-oxide stained and containing quartz veins. Several pieces with slickenslides and moderately gossanous. \\
\hline $2003 Z 214 \mathrm{~B}$ & 429596 & 7268758 & Silicified dolomite with disseminated pyrite and pyrite in clots and stringers. \\
\hline $2003 Z 239 \mathrm{~B}$ & 429297 & 7266656 & Conglomerate with common white $1-10 \mathrm{~mm}$ wide quartz veins and locally gossanous iron oxide. \\
\hline $2003 Z 243 \mathrm{~A}$ & 429681 & 7267608 & Sucratic quartzite with disseminated pyrite and veinlets of quartz, pyrite, and arsenopyrite. \\
\hline 2003Z244A & 429690 & 7267575 & $\begin{array}{l}\text { Sulfide-bearing quartzite breccia; } 1 \mathrm{ft} . \times 1 \mathrm{ft} . \times 6 \text { in. cobble with brecciated texture; other cobbles are quartz-veined. Malachite, pyrite, and } \\
\text { arsenopyrite (1-2\% of rock) in veinlets. }\end{array}$ \\
\hline $2003 Z 248 \mathrm{~A}$ & 428833 & 7267311 & Low temperature silicification; quartz as botryoidal, drusy, and opalescent. Weak iron-oxide stains. \\
\hline 2003Z255A & 427758 & 7266231 & abbro with finely disseminated pyrite and minor chalcopyrite. Some chlorite alteration in open fractures. \\
\hline
\end{tabular}


Table 5. Limits and analytical methods for the major-oxide, minor-oxide, and trace-element analyses. Analytical method XRF = X-ray Fluorescence Spectrometry.

\begin{tabular}{|c|c|c|c|}
\hline $\begin{array}{c}\text { Elemental Oxide } \\
\text { or Element }\end{array}$ & $\begin{array}{c}\text { Analytical } \\
\text { Method }\end{array}$ & $\begin{array}{c}\text { Lower Detection } \\
\text { Limit }\end{array}$ & $\begin{array}{c}\text { Upper Detection } \\
\text { Limit }\end{array}$ \\
\hline $\mathrm{SiO} 2$ & $\mathrm{XRF}$ & $0.01 \%$ & $100 \%$ \\
\hline $\mathrm{Al2O} 3$ & $\mathrm{XRF}$ & $0.01 \%$ & $100 \%$ \\
\hline $\mathrm{Fe} 2 \mathrm{O} 3$ & $\mathrm{XRF}$ & $0.01 \%$ & $100 \%$ \\
\hline $\mathrm{CaO}$ & $\mathrm{XRF}$ & $0.01 \%$ & $100 \%$ \\
\hline $\mathrm{MgO}$ & $\mathrm{XRF}$ & $0.01 \%$ & $100 \%$ \\
\hline $\mathrm{Na} 2 \mathrm{O}$ & $\mathrm{XRF}$ & $0.01 \%$ & $100 \%$ \\
\hline $\mathrm{K} 2 \mathrm{O}$ & $\mathrm{XRF}$ & $0.01 \%$ & $100 \%$ \\
\hline $\mathrm{Cr} 2 \mathrm{O} 3$ & $\mathrm{XRF}$ & $0.01 \%$ & $100 \%$ \\
\hline $\mathrm{TiO} 2$ & $\mathrm{XRF}$ & $0.01 \%$ & $100 \%$ \\
\hline $\mathrm{MnO}$ & $\mathrm{XRF}$ & $0.01 \%$ & $100 \%$ \\
\hline $\mathrm{P} 2 \mathrm{O} 5$ & $\mathrm{XRF}$ & $0.01 \%$ & $100 \%$ \\
\hline $\mathrm{SrO}$ & $\mathrm{XRF}$ & $0.01 \%$ & $100 \%$ \\
\hline $\mathrm{BaO}$ & $\mathrm{XRF}$ & $0.01 \%$ & $100 \%$ \\
\hline $\mathrm{LOI}$ & $\mathrm{XRF}$ & $0.01 \%$ & $100 \%$ \\
\hline $\mathrm{Total}$ & $\mathrm{XRF}$ & $0.01 \%$ & $100 \%$ \\
\hline $\mathrm{Ba}$ & $\mathrm{XRF}$ & $10 \mathrm{ppm}$ & $10,000 \mathrm{ppm}$ \\
\hline $\mathrm{Nb}$ & $\mathrm{XRF}$ & $2 \mathrm{ppm}$ & $10,000 \mathrm{ppm}$ \\
\hline $\mathrm{Rb}$ & $\mathrm{XRF}$ & $2 \mathrm{ppm}$ & $10,000 \mathrm{ppm}$ \\
\hline $\mathrm{Sr}$ & $\mathrm{XRF}$ & $2 \mathrm{ppm}$ & $10,000 \mathrm{ppm}$ \\
\hline $\mathrm{Y}$ & $\mathrm{XRF}$ & $2 \mathrm{ppm}$ & $10,000 \mathrm{ppm}$ \\
\hline $\mathrm{Zr}$ & $\mathrm{XRF}$ & $2 \mathrm{ppm}$ & $10,000 \mathrm{ppm}$ \\
\hline
\end{tabular}


Table 6. Limits and analytical methods for trace-element geochemical analysis.

Analytical methods include: FA-AAS = Fire Assay-Atomic Absorption Spectroscopy, ICP-MS = Inductively Coupled Plasma-Mass Spectroscopy, ICP-AES = Inductively Coupled Plasma-Atomic Emission Spectroscopy, CV-AAS = Cold Vapor-Atomic Absorption Spectroscopy

\begin{tabular}{|c|c|c|c|}
\hline Element & Analytical Method & Lower Detection Limit & Upper Detection Limit \\
\hline Au1 & FA-AAS & $0.005 \mathrm{ppm}$ & $10 \mathrm{ppm}$ \\
\hline Au2 & ICP-MS & $0.001 \mathrm{ppm}$ & $1 \mathrm{ppm}$ \\
\hline Au3 & FA-Gravimetric & $0.05 \mathrm{ppm}$ & $1,000 \mathrm{ppm}$ \\
\hline $\mathrm{Pt}$ & ICP-MS & $0.0005 \mathrm{ppm}$ & 1 ppm \\
\hline $\mathrm{Pd}$ & ICP-MS & $0.001 \mathrm{ppm}$ & $1 \mathrm{ppm}$ \\
\hline $\mathrm{Ag}$ & ICP-AES & $0.5 \mathrm{ppm}$ & 100 ppm \\
\hline $\mathrm{Al}$ & ICP-AES & $0.01 \%$ & $25 \%$ \\
\hline As1 & ICP-AES & $5 \mathrm{ppm}$ & $10,000 \mathrm{ppm}$ \\
\hline As2 & Aqua Regia-AAS & $0.01 \%$ & $30 \%$ \\
\hline $\mathrm{Ba}$ & ICP-AES & 10 ppm & $10,000 \mathrm{ppm}$ \\
\hline $\mathrm{Be}$ & ICP-AES & $0.5 \mathrm{ppm}$ & 1000 ppm \\
\hline $\mathrm{Bi}$ & ICP-AES & $2 \mathrm{ppm}$ & $10,000 \mathrm{ppm}$ \\
\hline $\mathrm{Ca}$ & ICP-AES & $0.01 \%$ & $25 \%$ \\
\hline $\mathrm{Cd}$ & ICP-AES & $0.5 \mathrm{ppm}$ & 500 ppm \\
\hline Co & ICP-AES & $1 \mathrm{ppm}$ & $10,000 \mathrm{ppm}$ \\
\hline $\mathrm{Cr}$ & ICP-AES & $1 \mathrm{ppm}$ & $10,000 \mathrm{ppm}$ \\
\hline $\mathrm{Cu}$ & ICP-AES & $1 \mathrm{ppm}$ & $10,000 \mathrm{ppm}$ \\
\hline $\mathrm{Fe}$ & ICP-AES & $0.01 \%$ & $25 \%$ \\
\hline $\mathrm{Hg}$ & CV-AAS & $0.01 \mathrm{ppm}$ & $100 \mathrm{ppm}$ \\
\hline $\mathrm{K}$ & ICP-AES & $0.01 \%$ & $10 \%$ \\
\hline $\mathrm{Mg}$ & ICP-AES & $0.01 \%$ & $15 \%$ \\
\hline $\mathrm{Mn}$ & ICP-AES & $5 \mathrm{ppm}$ & 10,000 ppm \\
\hline Mo & ICP-AES & $1 \mathrm{ppm}$ & $10,000 \mathrm{ppm}$ \\
\hline $\mathrm{Na}$ & ICP-AES & $0.01 \%$ & $10 \%$ \\
\hline $\mathrm{Ni}$ & ICP-AES & $1 \mathrm{ppm}$ & 10,000 ppm \\
\hline $\mathrm{P}$ & ICP-AES & 10 ppm & $10,000 \mathrm{ppm}$ \\
\hline $\mathrm{Pb}$ & ICP-AES & $2 \mathrm{ppm}$ & $10,000 \mathrm{ppm}$ \\
\hline$S$ & ICP-AES & $0.01 \%$ & $10 \%$ \\
\hline $\mathrm{Sb}$ & ICP-AES & $5 \mathrm{ppm}$ & $10,000 \mathrm{ppm}$ \\
\hline $\mathrm{Sr}$ & ICP-AES & $1 \mathrm{ppm}$ & $10,000 \mathrm{ppm}$ \\
\hline $\mathrm{Ti}$ & ICP-AES & $0.01 \%$ & $10 \%$ \\
\hline $\mathrm{V}$ & ICP-AES & $1 \mathrm{ppm}$ & $10,000 \mathrm{ppm}$ \\
\hline W & ICP-AES & $10 \mathrm{ppm}$ & $10,000 \mathrm{ppm}$ \\
\hline $\mathrm{Zn}$ & ICP-AES & $2 \mathrm{ppm}$ & $10,000 \mathrm{ppm}$ \\
\hline
\end{tabular}


